\title{
Development of colonic sodium transport in early childhood and its regulation by aldosterone
}

\author{
H R Jenkins, T R Fenton, N McIntosh, M J Dillon, P J Milla
}

\begin{abstract}
Aldosterone is important in the regulation of sodium conservation by both kidney and colon. In the very preterm neonate marked urinary salt wasting occurs because of immature renal tubular function, but little is known of the ontogeny of colonic transport processes. Using an in vivo rectal dialysis technique, we have shown that in the human infant the colon has well developed salt conserving mechanisms from early in the last trimester of gestation and that aldosterone is an important regulatory hormone. Sodium transport mechanisms in the colon appear to develop before those in the kidney and it is possible that the colon is the major organ of sodium conservation in the preterm neonate.
\end{abstract}

Disturbances in salt and water homeostasis develop more readily in infancy than later in life at a time when brain development is occurring rapidly and adequate nutrition and conservation of fluid and electrolytes are vital for optimal growth.' The maintenance of electrolyte and water balance in the growing child is achieved by satisfactory renal tubular function and a normally functioning gastrointestinal tract, with the colon, in particular, playing an important part.

In adult man aldosterone is known to play a critical role in the regulation of sodium conservation by kidney and colon, and in young infants it has been reported that circulating aldosterone levels are high. ${ }^{23}$ Despite this relative hyperaldosteronism, however, urinary salt wasting occurs which is most marked in the very preterm infant $^{+6}$ and may be related to the state of development of the renal tubule.

There are close homologies between the transport processes of the renal tubule and the colon, and active absorption of sodium has been shown in the colon of adult humans and experimental animals. ${ }^{7-11}$ To date there have been no systematic studies of the development of colonic mechanisms for sodium absorption in infancy or their regulation by aldosterone. In view of the renal sodium wasting in very preterm infants, the colon may assume greater importance in salt and water homeostasis. We have therefore investigated colonic sodium absorption in preterm neonates, infants, and older children and the importance of aldosterone as a regulatory hormone.

\section{Methods}

\section{PATIENTS}

Patients were put into the following groups: (a) preterm neonates, gestational age 30-33 weeks $(\mathrm{n}=15)$; (b) preterm neonates, gestational age 34-37 weeks $(n=14)$; (c) full term neonates gestational age 38-44 weeks $(n=5)$; (d) infants, age $1-12$ months $(n=17)$; (e) older children, age 1-8 years $(n=19)$; $(f)$ children with end organ unresponsiveness to aldosterone (pseudohypoaldosteronism $=$ PHA), age $6-12$ months $(n=2)$; (g) children with aldosterone deficiency (congenital adrenal hyperplasia, 21-hydroxylase defect $=\mathrm{CAH})$, age $6-18$ months $(n=3)$. Patients in group (g) were studied: (i) while receiving their usual mineralocorticoid and glucocorticoid supplements and (ii) 48 hours after discontinuing mineralocorticoid supplements. Normal plasma sodium concentrations were maintained during this period by increased oral sodium supplementation; (h) children with secondary hyperaldosteronism (congenital chloride-losing diarrhoea $=C C D)$, age $10-24$ months $(n=2)$.

Rectal sodium absorption was measured in groups (a)-(c) in the second week of post natal life to avoid changes caused by acute fluctuations in electrolyte and fluid balance induced by labour and delivery. Plasma aldosterone was measured in seven infants in group (a) and four infants in group (b) and compared with previously published reference data for children in groups (c)-(e) derived by one of us (MJD) using the same assay in the same laboratory.

Infants in groups (a)-(e) had remained in hospital after birth because of feeding difficulties or mild respiratory problems. All were fed enterally and none was ventilated. Children in groups (d) and (e) were in the recovery phase after medical admission for a variety of problems. Children in groups $(\mathrm{f}),(\mathrm{g})$, and $(\mathrm{h})$ were studied during admission for further investigation of their disease. None of the children studied had large intestinal disease and none (except group h) showed evidence of diarrhoea.

Electrolyte transport by the rectum and rectal potential difference (pd) were measured by a non-equilibrium dialysis method as previously described ${ }^{12}{ }^{13}$ using dialysis bags of 3 or $4 \mathrm{~cm}$ in length, depending on the size of the child. No recordings of transmural pd were made during studies of preterm neonates, however, as the insertion of a subcutaneous needle was not felt to be justified in such tiny infants. The initial dialysis electrolyte solution was isotonic and contained $\mathrm{Na} 140, \mathrm{~K} 20, \mathrm{Cl} 130$, and $\mathrm{HCO}_{3} 30$ $\mathrm{mmol} / \mathrm{l}$; the electrolyte concentrations of the dialysate before and after the one hour incubation were measured by flame photometry in a 5-channel Auto-Analyzer. Specimens showing faecal contamination were discarded. It has been shown that the dialysis membrane itself provides no diffusional barrier, and the majority of electrolyte and water movement occurs across the mucosa in contact with the dialysis bag. ${ }^{12}$ It is 
assumed that the thin intermediate fluid layer between the dialysis bag and the empty rectum behaves as a compartment of small capacity and thus, as the dialysis membrane is so much more permeable than the gut epithelium, the concentration of electrolytes in the fluid layer rapidly approximates to its concentration in the tube; thus a steady state is reached and the presence of the dialysis membrane can be ignored.

In this study net movements of sodium and potassium across the rectal mucosa were calculated and expressed per unit area of mucosa using the following standard formula: ${ }^{12}$

$$
\mathrm{Jn}=1000 \times \frac{\mathrm{V}_{\mathrm{o}} \mathrm{I}_{\mathrm{o}}-\mathrm{V}_{\mathrm{t}} \mathrm{I}_{\mathrm{t}}}{\mathrm{A} \times \mathrm{t}} \mathrm{nmol} / \mathrm{min} / \mathrm{cm}^{2}
$$

where $\mathrm{Jn}=$ net movement; $\mathrm{V}$ and $\mathrm{I}=$ the volume of the tube in millilitres and the concentration of the ion in $\mathrm{mmol} / \mathrm{l}$ respectively; $A=$ the surface area of the dialysis bag in $\mathrm{cm}^{2}$ and $\mathrm{t}=$ the time of exposure in minutes; the subscripts $o$ and $t$ refer to initial and final values.

Plasma aldosterone concentrations were measured before performing rectal dialysis and analysed as previously described. ${ }^{14}$ Plasma electrolytes were normal in all patients, and studies were performed at the same time of the day (morning) to avoid differences induced by the diurnal variation in aldosterone secretion.

Mean values \pm 1 SD were calculated and the groups compared using one-way analysis of variance. ${ }^{15}$ The studies were approved by the ethical committees of the Hospitals for Sick Children and St George's Hospital, and informed, written consent was obtained from the infants' parents.

\section{Results}

RECTAL SODIUM ABSORPTION, POTASSIUM SECRETION, AND PLASMA ALDOSTERONE CONCENTRATIONS IN INFANCY AND CHIL DHOOD(Table I)

Sodium absorption was highest in (a) 315 (62) $\mathrm{nmol} / \mathrm{min} / \mathrm{cm}^{2}$ (mean (SD)) falling progressively to near adult values ${ }^{12}$ in (e) $149(44) \mathrm{nmol} / \mathrm{min} /$ $\mathrm{cm}^{2}$. Using a one-way analysis of variance, there was a significant variation between the five groups (a)-(e) at the $5 \%$ level. To determine which particular groups were significantly different from each other we used Student-NewmanKeuls multiple comparisons procedure ${ }^{15}$ at the $5 \%$ significance level. Groups (a) and (b) were not significantly different from each other but

TABLE I Rectal sodium absorption, potassium secretion, potential difference, and plasma aldosterone concentrations in children of different ages (groups $a-e$ )

\begin{tabular}{|c|c|c|c|c|c|}
\hline & $\begin{array}{l}\text { (a) } \\
\text { Preterm neonates } \\
\text { ga } 30-33 \text { wks }\end{array}$ & $34-37$ wks & $\begin{array}{l}\text { (c) } \\
\text { Term neonates } \\
38-44 \text { wks }\end{array}$ & $\begin{array}{l}\text { (d) } \\
\text { Infants } \\
l-12 \mathrm{mo}\end{array}$ & $\begin{array}{l}\text { (e) } \\
\text { Children } \\
1-8 \text { yrs }\end{array}$ \\
\hline $\begin{array}{l}\mathrm{n} \\
\mathrm{Na} \text { abs } \\
\mathrm{K} \text { sec } \\
\mathrm{P} \text { aldo } \\
\text { PD }\end{array}$ & $\begin{array}{c}15 \\
315(62) \\
38(36) \\
5464(3810) \\
\text { NM }\end{array}$ & $\begin{array}{c}14 \\
302(67) \\
37(30) \\
3085(2080) \\
\text { NM }\end{array}$ & $\begin{array}{c}5 \\
243(36) \\
47(31) \\
1248(380) \\
43(12)\end{array}$ & $\begin{array}{c}17 \\
203(50) \\
27(20) \\
780(295) \\
38(10)\end{array}$ & $\begin{array}{c}19 \\
149(44) \\
33(26) \\
240(190) \\
39(11)\end{array}$ \\
\hline
\end{tabular}

$\mathrm{n}=$ number of patients studied in each group; $\mathrm{Na}$ abs $=$ rectal sodium absorption; $\mathrm{K} \mathrm{sec}=$ rectal potassium secretion in $\mathrm{nmol} / \mathrm{min} / \mathrm{cm}^{\prime} ; \mathrm{P}$ aldo $=$ plasma aldosterone in $\mathrm{pmol} / \mathrm{l} ; \mathrm{PD}=$ rectal potential difference in $\mathrm{mV}$; ga = gestational age; $\mathrm{NM}=$ not measured. Figures show mean (SD). both were significantly different from (c)-(e); of groups (c)-(e), (c) and (d) were not significantly different from each other whereas (e) was significantly different from both (c) and (d). There were no significant differences in potassium secretion between groups (a)-(e).

Plasma aldosterone concentrations were markedly raised in preterm neonates, (a) 5464 (3810) and (b) 3085 (2080) pmol/l, when compared with previously published aldosterone concentrations for full term neonates, 1248 (380) $\mathrm{pmol} / \mathrm{l}$, and infants 780 (295) pmol/l.' Rectal sodium absorption and plasma aldosterone values were closely associated throughout infancy and childhood.

RECTAL SODIUM ABSORPTION, POTASSIUM SECRETION, POTENTIAL DIFFERENCE, AND PLASMA ALDOSTERONE

CONCENTRATIONS IN CHILDREN WITH DISORDERED ALDOSTERONE METABOLISM (Table II)

In age matched control children $(n=14)$ rectal sodium absorption was 183 (34) and potassium secretion $33(23) \mathrm{nmol} / \mathrm{min} / \mathrm{cm}^{2}$ with rectal potential difference $39(9) \mathrm{mV}$ (mucosa negative with respect to serosa) and plasma aldosterone 720 (280) pmol/l. In PHA (f), however, there was markedly reduced rectal sodium absorption, 71 and 101 , potassium secretion, 0 and $5 \mathrm{nmol} / \mathrm{min} /$ $\mathrm{cm}^{2}$, and reduced rectal potential difference, 7 and $9 \mathrm{mV}$, despite very high concentrations of circulating aldosterone, 3900 and $10500 \mathrm{pmol} / \mathrm{l}$, suggesting an unresponsiveness of colonic reabsorptive mechanisms to aldosterone.

In CAH (g), after 48 hours without mineralocorticoid supplementation, plasma aldosterone concentrations were unrecordable in the three patients and rectal sodium absorption, 55, 68, 46 , and potassium secretion $0,2,6 \mathrm{nmol} / \mathrm{min}$ $\mathrm{cm}^{2}$, and potential difference, $13,18,25 \mathrm{mV}$, were greatly reduced compared with controls. When studied previously during a period of adequate mineralocorticoid supplementation, these patients in $(\mathrm{g})$ yielded results not significantly different from the control group (sodium absorption 148, 153, 130 and potassium secretion $31,37,15 \mathrm{nmol} / \mathrm{min} / \mathrm{cm}^{2}$ and potential difference $35,54,40 \mathrm{mV}$ ), indicating the importance of aldosterone in promoting rectal sodium absorption.

In CCD (h), a condition in which colonic sodium reabsorptive mechanisms are unimpaired, rectal sodium absorption, 368 and $312 \mathrm{nmol} / \mathrm{min} / \mathrm{cm}^{2}$, potassium secretion 107, $50 \mathrm{nmol} / \mathrm{min} / \mathrm{cm}^{2}$ and rectal potential difference, 98 and $87 \mathrm{mV}$, were markedly raised, presumably because of the very high concentrations of circulating plasma aldosterone, 9750 and $1240 \mathrm{pmol} / \mathrm{l}$, reflecting the secondary hyperaldosteronism found in these patients.

\section{Discussion}

Young children are particularly prone to disturbances of electrolyte and water homeostasis. In the older child and adult, renal function is mature, but in the preterm neonate there is glomerulotubular imbalance and a relative renal 
TABLE II Rectal sodium absorption, potassium secretion, potential difference, and plasma aldosterone concentrations in children with disordered aldosterone metabolism and age matched controls (groups $f-i$ )

\begin{tabular}{llllll}
\hline & $(f)$ & $(g-)$ & $(g+)$ & $(h)$ & $(i)$ \\
\hline $\mathbf{n}$ & 2 & 3 & 3 & 2 & 14 \\
Na abs & 71,101 & $55,68,46$ & $148,153,130$ & 368,312 & $183(34)$ \\
K sec & 0,5 & $0,2,6$ & $31,37,15$ & 107,50 & $33(23)$ \\
P aldo & 3900,10500 & $0,0,0$ & NM & 9750,1240 & $720(280)$ \\
PD & 7,9 & $13,18,25$ & $35,54,40$ & 98,87 & $39(9)$ \\
\hline
\end{tabular}

$(\mathrm{f})=$ children with pseudohypoaldosteronism; $(\mathrm{g})=$ children with congenital adrenal hyperplasia,$(\mathrm{g}-)$ studied after withholding corticosteroid supplements; $(\mathrm{g}+)$ after corticosteroid supplements administered; $(h)=$ children with congenital chloride-losing diarrhoea; $(i)=$ age-matched controls. Other abbreviations as in Table I with figures showing individual patient results in groups $(f)-(h)$ and mean $(\mathrm{SD})$ in group $(\mathrm{i})$. dependent ion-transporting epithelia, including the colon. Thus despite the very high circulating concentrations of aldosterone found in these patients, rectal sodium absorption was markedly reduced. In salt-losing congenital adrenal hyperplasia, the defect is in mineralocorticoid production, resulting in aldosterone deficiency. After discontinuing exogenous mineralocorticoid for 48 hours, both rectal sodium absorption and potential difference fell dramatically in our patients, while previous studies during adequate mineralocorticoid supplementation produced results not significantly different from age matched controls. The two patients with congenital chloride-losing diarrhoea showed greatly increased rectal sodium absorption and potential difference associated with very high circulating concentrations of aldosterone, providing further evidence for the crucial role that aldosterone appears to play in colonic transport. It is also well known that increased concentrations of aldosterone are associated with colonic potassium secretion, ${ }^{28}$ and the increase in rectal potassium secretion in one of the children with secondary hyperaldosteronism seen in our study was predictable. The potassium secretion is largely driven by the electrical gradient which is produced by sodium absorption; thus stimulation of sodium absorption by aldosterone will result in an increased transmural potential difference and therefore increased potassium secretion. It is noteworthy that rectal potential difference and rectal potassium secretion were similar in groups (c)-(e). Unfortunately, rectal potential difference was not measured in the preterm neonates (group a-b) but, despite high circulating aldosterone concentrations and increased rectal sodium absorption in these babies, there was no significant increase in rectal potassium secretion. The reasons for this difference in very young infants are unclear, but may be related to a delayed maturation of active potassium secretion. Indeed, in the fetal lamb kidney, aldosterone appears to promote sodium reabsorption, but it has no simultaneous effect on potassium secretion until the last trimester of gestation. ${ }^{29}$

Our observations do not provide any evidence for the mechanism by which aldosterone might promote sodium absorption in developing human colon. Recent observations in adult rat distal colon, however, suggest that the prime effect of aldosterone is on the amiloride sensitive electrogenic component of net sodium absorption. ${ }^{18}$ In the suckling and weanling rat net sodium absorption occurs only through an amiloride sensitive channel,,$^{30}$ although studies in newborn pig distal colon suggest that the increase in concentrations of circulating aldosterone immediately after birth may induce a change in sodium transport from an amiloride insensitive to an amiloride sensitive electrogenic mechanism in the early neonatal period. ${ }^{31}{ }^{32}$ In human weanling distal colon net sodium uptake is entirely accounted for by short circuit current and is also amiloride sensitive. ${ }^{33}$ It seems highly likely, therefore, that the effect of chronically high circulating concentrations of aldosterone in the preterm infant is to promote increased sodium absorption by the induction of amiloride ant regulatory factor is provided by the close association between plasma aldosterone and rectal sodium absorption, and the fact that rectal absorption of sodium is greatly affected by differing states of aldosterone metabolism (Table II). In pseudohypoaldosteronism there appears to be a generalised defect of mineralocorticoid 
sensitive electrogenic sodium absorption. Our data regarding sodium absorption, potential difference and aldosterone concentrations in older infants with defects in aldosterone metabolism are at least consistent with this hypothesis.

In conclusion, our studies have shown for the first time that colonic sodium transport mechanisms are efficient in very early infancy, and that aldosterone is an important regulatory influence. In view of the relative renal immaturity in the preterm neonate, the colon may be of particular importance in overall sodium and water homeostasis in this age group.

HRJ was in receipt of a Training Research Fellowship from Action Research for the Crippled Child.

1 Milla PJ, Trompeter R, Dillon MJ, Shackleton C. Salt-losing syndrome in 2 infants with defective 18-dehydroge in aldosterone biosynthesis. Arch Dis Child 1977; 52: 580-6.

2 Dillon MJ, Gillin MEA, Ryness JM, DeSwiet M. Plasma renin activity and aldosterone concentration in the human newborn. Arch Dis Child 1976; 51: 537-40.

3 Sulyok E, Nemeth M, Tenyi I, et al. Postnatal development of renin-angiotensin-aldosterone system, RAAS, in relation to renin-angiotensin-aldosterone system, RAAS, in relation to
electrolyte balance in premature infants. Pediatr Res 1979; 13: $817-20$.

4 Aperia A, Broberger O, Elinder G, Herin P, Zetterstrom R. Post natal development of renal function in preterm and full Post natal development of renal function in preter

5 Arant $\mathrm{B}$. Developmental patterns of renal functional maturation compared in the human neonate. $\mathcal{F}$ Pediatr 1978; 92 705-12.

6 Aperia A, Broberger O, Thodenius K, Zetterstrom R. Renal control of sodium and fluid balance in newborn infants during intravenous maintenance therapy. Acta Paediatr Scand 1975; 64: 725-31.

7 Devroede GJ, Phillips SF. Conservation of sodium, chloride and water by the human colon. Gastroenterology $1969 ; 56$ : 101-9.

8 Frizzel RA, Koch MJ, Schultz SG. Ion transport by rabbit colon. 1. Active components. F Membr Biol 1976; 27: 297 316.

9 Giller J, Phillips SF. Electrolyte absorption and secretion in the human colon. Dig Dis Sci 1972; 17: $1003-11$.

10 Grady GF, Duhamel RC, Moore EW. Active transport of sodium in the human colon in vivo. Gastroenterology 1970; 11: $330-7$.

11 Hawker PC, Mashiter KE, Turnberg LA. Mechanisms of transport of $\mathrm{Na}, \mathrm{Cl}$ and $\mathrm{K}$ in the human colon. Gastroenterology 1978; 74: 1241-7.

12 Edmonds CJ. Absorption of sodium and water by human rectum measured by a dialysis method. Gut 1971 ; 12: 35662.

13 Savage MO, Jefferson IG, Dillon MJ, Milla PJ, Honour JW, Grant DB. Pseudohypoaldosteronism: severe salt wasting in infancy caused by generalised mineralocorticoid unresponsiveness. F Pediatr 1982; 101: 239-42.

14 Dillon MJ, Ryness JM. Plasma renin activity and aldosterone concentration in children. Br Med F 1975; 4: 316.

15 Armitage P. Berry G. Statistical methods in medical research. 2nd ed. Oxford: Blackwell, 1983.

16 Al-Dahan J, Haycock GB, Chantler C, Stimmler C. Sodium homeostasis in term and preterm neonates: 1 . Renal aspects. Arch Dis Child 1983; 58: 335-42.

17 Jorkasky V, Cox M, Feldman GM. Differential effects of corticosteroids on $\mathrm{Na}$ transport in rat distal colon in vitro. Am F Physiol 1985; 248: 424-31.

18 Halevy J, Buclinger ME, Hayslett JP, Binder HJ. Role of aldosterone in the regulation of sodium and chloride transport in the distal colon of sodium-depleted rats. Gastroenterologv 1986; 91 : 1227-33.

19 Will PC, Cortright RN, De Lisle RC, Douglas JG, Hopfer U. Regulation of amiloride-sensitive electrogenic sodium transport in the rat colon by steroid hormones. Am 7 Physiol 1985; 248: 124-32.

20 Sandle GI, Hayslett JP, Binder HJ. Effect of glucocorticoid on rectal transport in normal subjects and patients with on rectal transport in normal subjects

21 I evitan R, Ingelfinger FJ. Effect of d-aldosterone on salt and water absorption from the intact human colon. 7 Clin Invest water absorption

22 Bastl CP, Barnett CA, Schmidt TJ, Litwack G. Glucocorticoid stimulation of sodium absorption in colon epithelia is mediated by corticosteroid $1 \mathrm{~B}$ receptor. $\mathcal{F}$ Biol Chem 1984 259: 1186-95.

23 Binder $\mathrm{HJ}$, White A, Whiting D, Hayslett J. Demonstration of specific high affinity receptors for aldosterone in cytosol of rat colon. Endocrinologv 1986; 118: 628-31.

24 Sulyok E, Kovacs L, Lichardus B, et al. I ate hyponatraemi in premature infants: role of aldosterone and arginine vasopressin. 7 Pediatr 1985; 106: $990-$

25 Thomas S, Murphy JF, Dyas J, Ryalls M, Hughes IA Response to ACTH in the newborn. Arch Dis Child 1986; 61 : $57-60$.

26 Few JD, Mangat TK, Oppe TE, James VHT. Saliva aldosterone in healthy infants. Arch Dis Child 1986; 61: 508-9.

27 Hubel KA, Renquist K, Shirazi S. Ion transport in human cecum, transverse colon and sigmoid colon in vitro. (jastroenterology 1987: 92:501-7.

28 Sandle GI, Binder HJ. Corticosteroids and intestinal ion transport. Gastroenterology 1987; 93: 188-96.

29 Robillard JE, Nakamura KT, Lawton WJ, Smith B, McWeeny O, Wear S. Effects of aldosterone on urinary kallikrein and sodium excretion during fetal life. Pediatr Res 1985; 19: 1048-52.

30 Finkel Y, Eklof AC, Aperia A. Mechanisms for colonic Na transport during ontogeny: loss of an amiloride-sensitive sodium pathway. Pediatr Res 1988; 24: 46-9.

31 Cremaschi D, Ferguson DR, Henın S, James PS, Meyer G, Smith MW. Post-natal development of amiloride sensitive Smith MW. Post-natal development of amiloride sensitive
sodium transport in pig distal colon. $\mathcal{F}$ Physiol 1979; 292: 481-94.

32 Ferguson DR, James PS, Paterson JYF, Saunders JC, Smith $\mathrm{MW}$. Aldosterone induced changes in colonic sodium transport occurring naturally during development in the neonatal pig. F Physiol 1979; 292: 495-504.

33 Jenkins HR, Schnackenberg U, Milla PJ. Mechanisms of transport of sodium and chloride and the effects of short chain fatty acids in the human infant colon [Abstract]. Pediatr Res 1987; 22: 97. 